\title{
Medical Doctors' Strike: An Ethical Overview with Reference to the Indian Context
}

Ramesh P Aacharya ${ }^{1 *}$ and Sibichan Varghese ${ }^{2}$

${ }^{1}$ Department of Emergency and General Practice, Tribhuvan University Teaching Hospital, Institute of Medicine, Maharajgunj, Kathmandu, Nepal

${ }^{2}$ Department of Higher Secondary Education, Omanoor P.O. Malappuram, Kerala, India

*Corresponding author: Ramesh P Aacharya, Department of Emergency and General Practice, Tribhuvan University Teaching Hospital, Institute of Medicine, Maharajgunj, Kathmandu, Nepal, Tel: 977-149-10466; E-mail: raacharya@yahoo.com

Received date: May 10, 2016; Accepted date: June 01, 2016; Published date: June 02, 2016

Copyright: (c) 2016 Aacharya RP, et al. This is an open-access article distributed under the terms of the Creative Commons Attribution License, which permits unrestricted use, distribution, and reproduction in any medium, provided the original author and source are credited

\begin{abstract}
Background: Medical doctors' strikes are a common global phenomenon. In the recent past, a number of strikes have been reported in various developing countries including India. The objective of this ethical overview is (a) to study and describe reasons, modalities and impacts of the doctors' strikes in India, (b) to develop an ethical reflection on doctors' strike and (c) to evaluate the doctors' strikes in India using this ethical reflection.

Discussion: In this literature based study, we discuss Indian doctors' strike and its various ethical reflections and assessment. This paper is arranged in three sections in accordance with the objectives of the study. In the first section, we analyse the Indian situation with doctors' strikes in terms of its reasons, modalities and its impacts. In second section, we elaborate a general ethical reflection on doctors' strike explored using normative ethical framework. General ethical reflection developed based on the Hippocratic Oath and other codes, biomedical principles like beneficence, non-maleficence and autonomy, as well as ethical approaches like deontological and utilitarian reasoning, and traditional Indian philosophy. The third section focuses on the assessment and evaluation of doctors' strikes based on ethical reflection developed in previous section.
\end{abstract}

Summary: Indian doctors' strikes are morally not acceptable and ethically not allowable based on deontological reasoning, Hippocratic tradition, different biomedical principles and ancient Indian philosophy. However, considering utilitarian reasoning, doctors' strikes for fair wage, better hospital infrastructure and working conditions are justifiable if it causes less harm to present patients and gives more good to the future patients.

Keywords: Doctors' strike; Collective actions; Indian health care system and medical ethics

\section{Background}

Strikes are usually collective actions that occur in all democratic societies. They always involve a joining together of individuals who stop their work for a certain period of time and who are united by common goals or interests. They use strikes in order to consolidate power for the purpose of negotiating with government or other groups. Different labor groups use different types of collective actions such as withholding labour actions or work slowdowns [1]. Thus strikes, in general, are a legitimate form of collective protest in a democratic country [2] and as such they are an important weapon that workers possess and use to increase their bargaining power as well as facilitating the process of negotiation towards agreeable result.

Health is a very important human value and hence health care is a paramount social good. In this context doctors have more responsibility on health of every people [3]. In many countries health care workers including doctors are unsatisfied with factors like payments and with non-monetary aspects such as healthcare policy issues, security and safety issues, better working conditions and hospital's physical and administrative infrastructure [4-12]. Doctors argue that they are compelled to action to make their needs or demands met, and that strikes may be chosen as an ultimate choice of action. Such collective actions by practicing doctors are occurring with increasing frequency worldwide [13-15]. In 2006, Frizelle pointed out that in the past two decades there has been strikes by medical doctors in many countries including Australia, Belgium, Canada, Chile, Finland, France, Germany, Ghana, India, Ireland, Israel, Italy, Korea, Malta, New Zealand, Peru, Serbia, Spain, Sri Lanka, Romania, USA, UK, Zambia and Zimbabwe [14]. Many of these strikes have been harmful to patients as strikes reduce patient's access to care by eliminating or delaying necessary care, and may, at times interfere with the continuity of such care $[16,17]$.

A doctors' strike, regardless of the reason for it, receives a lot of media attention and meets a great deal of criticism and resistance from the general public as well as within the healthcare profession $[18,19]$. In fact, it arouses intense debate on the ethical justification of medical professionals failing to prioritise human life and their needs, and to find less harmful ways of negotiating their own needs without harming patients [20-22]. Many empirical studies and reviews on strikes indicate that in many instances, medical services are badly affected by doctors' strikes $[7,15]$. The objections against medical strikes range from causing harm to patients, deterioration of physician-patient relationship to decrease of public's respect for the medical profession [23].

In the recent past, a number of such strikes have been reported from many developing countries including India [4-7,10,24]. The impact of such strikes is very destructive in developing countries like India where 
medical insurance and health care systems are very poor and substandard. Pandya pointed out that "in such a (strike) situation, the paralysis of health care centres by striking doctors runs contrary to the raison d'être of the profession. It also violates the first dictum of medicine - Primum, non nocere" [25]. Although doctors usually put forward reasons to justify their strikes, such strikes need close ethical scrutiny. Significantly, striking doctors may feel psychological distress and ethical conflict regarding the consequences and impact of their strikes on patients [26]. In such a complex situation, various ethical dilemmas arise, like the legitimacy of doctors' strikes while patients are harmed [18], which further questions whether a medical doctor has autonomy to engage in what he/she feels to be his/her right. In this context our question is whether doctors' strikes can be ethically legitimate, especially in the Indian scenario? Do they have the right to strikes or work slowdowns, even if they have a genuine reason, which may put the lives of defenceless patients at serious danger? How can doctors genuinely press for their demands without making untoward effects to human life? Therefore, in this article we would like to discuss doctors' strikes and its ethical reflection with special reference to India. This ethical debate is literature based for which various databases and online sources including PubMed, Web of Science, Google Scholar, Philosophers index etc. were used. Most of the full texts were accessed through Health Internetwork Access to Research Initiative (HINARI) currently named as HINARI Access to Research in Health Programme. The objective of this work is to study and describe reasons, modalities and impacts of the doctors' strikes in India. Further, we try to develop an ethical reflection on doctors' strikes and to evaluate the doctors' strikes in India using these ethical reflections.

\section{Discussion}

\section{The Indian situation with doctors' strikes}

In India, strikes of junior as well as senior doctors have been more frequent in recent times which cause harm in different dimensions of a patient's life giving rise to ethical debates [21,22,27,28].

1a. Reasons for doctors' strike in India: Considering inadequate Indian public health care system, doctors argue that there are good reasons for carrying out strikes. They also argue that they deploy such activities when situations are hopeless and helpless, especially when dissatisfaction has become substantially worse. The major reasons can be categorised as follows:

Low wages: The main discontent for majority of doctors relates to a 'fair wage' [29]. The 'stipend' given to resident doctors are very low and they need to work increasingly longer hours and thus junior doctors are exploited by the administration bypassing all labour laws in the name of training. For this reason junior or resident doctors are leading groups to strike all over the world including India. Most of the senior doctors also receive a relatively low salary compared to their time at work, risks and expertise. Failure to fulfil their expectations has contributed to a 'brain drain' to the rich and developed countries.

Lack of security and safety at work places: Another reason for doctor's strike is increasing incidents of attacks on doctors [6,7], by relatives of certain unfortunate patients who lost their lives during the course of treatment. Such incidents increase the lack of security and safety in their working environments.

Health care policy issues: Another main reason for doctors'strikes is related with health care policy issues adopted by central or state governments $[4,5,10,24]$, which hamper the opportunity of a majority of talented and committed doctors to further their academic or professional and financial advancement.

Upgrading of institutional capacity: A number of strikes were also reported for better working conditions and for hospital infrastructure development [6,7]. The infrastructures in hospitals including professional resources are inadequate to accommodate the needs of all patients seeking for public hospital services. The number of medical staff is lower in every public hospital than is required. In many hospitals, many posts for medical staff remain vacant, and the attempts to get new recruits are inadequate and ineffective. Despite the fact that medical education infrastructure has grown rapidly during the last decade enrolling 46,456 medical students in 2014 [30] which is $64 \%$ increment compared to 2005 , the doctor-patient ratio is unsatisfactory with one government doctor for every 11,528 people [31]. Therefore, overcrowded public hospitals are very common in India, putting more pressure on the shoulders of public hospital doctors.

1b. Modes of Strike: Unlike what workers often do in other strikes, most striking doctors do not begin by sudden abandoning of patients in critical conditions [32]. Rather, the usual course is starting from simple work slow-down and then, gradual increase in intensity to strong actions. Initially, they may stop indoor admissions, not attend medical boards meetings. Later, they may deny services to out-patients and also exclude surgeries. However, in most cases, emergency departments are attended by some doctors during the strike. Most of such strikes last for one day to a few weeks, and the modes of striking differ from one situation to other. Doctors conduct demonstration [6], sit-in, absenteeism and some of them even undergo hunger strikes $[5,29,33]$.

1c. Impact of doctors' strikes: The impact of such strikes varies depending on a number of factors such as the duration, cases under treatment and mode of strike [2]. Most patients who come from poor backgrounds and seek for free healthcare, they are harmed greatly because they have neither medical insurance nor social security insurance. According to United Nation's Millennium Development Goal (MGD) programme 21 per cent out of India's population of 1.29 billion are living below the poverty line [34]. Further, in India, only less than 10 per cent of people have comprehensive health insurance coverage. This worsens their poor condition ending in sometimes very fatal results because they cannot financially afford to go to private hospitals. Thus outcomes of physicians' strikes are likely to affect patients and their vulnerability to illness makes patients relatively powerless in relationship to the health care system, and influencing patients' attitudes (of trust) towards medical doctors [1,26,35]. In India, there is a system of employing part time or alternative service especially doctors from army during periods of strike. The relatively small number of such part-time and/or full-time consultants in most departments is insufficient in comparison to the patients' load of those who are seriously ill requiring hospital care. According to Pandya ".... If doctors in such hospitals go on strike, the only option open to these patients is to turn their faces to the wall, sicken further, and, in some instances, die. These are compounded, avoidable tragedies, all the more terrible as they follow no fault of their" [25]. This statement clearly illustrates the depth of the consequences of doctors' strikes in India, which, in concluding this section, brings us back to our former question of whether it is ethically justifiable for doctors to demand to strike. The professional virtues behind such strikes raise moral and ethical questions. 


\section{Doctors' strike: a general ethical reflection}

2a. Are doctors' strikes ethically justifiable? Most early literary writings on ethics of physician strikes were analyzed in terms of justice, rights, or moral duties [36,37]. In addition to these, recent debates and literature on doctors' strike give more emphasize to trust-relationship, non-maleficence, autonomy, and professionalism etc. [23,38-42]. There are ongoing discussions and debates regarding the ethical justification of doctor's strike around the world. However, the ethical basis for these arguments can be found in Kant's second formulation of the categorical imperative: always treat other persons as having individual moral worth and dignity and never treat them merely as a means to one's own ends. Reitemeier believes that adherence to a few basic ethical principles is required for any protest action that impacts patient care [16]. Otherwise, the lay individual cannot empathize with the notion that highly educated and literate individuals such as medical doctors deign to take industrial action. In theory, a doctors' profession differs from other workers in that their primary goals are not making money but of saving the lives of patients with whom they have a fiduciary commitment. Therefore physicians should serve the interests of their patients according to their professional commitments above and beyond their own personal and immediate interests [39]. Jackson opined that in the event of a physicians' strike for personal financial gain, even if it were possible to delude patients that such a strike was really for 'their own good', the action would go against the collective conscience of the profession [38]. Only as a last resort and that under almost inconceivable conditions, might a total strike of health care professionals be justified [32] and one of these conditions is, that their actions will not harm the lives of their patients. Such justification could vary across different countries and contexts based on their political, social and cultural background. Health care system is also different between nations on account of its structure, funding, infrastructure etc. which is unique to each country. In the medical profession there are a set of shared values which relate to their behavior towards their patients. This behavior is regulated by guidelines, recommendations and biomedical principles.

2b. Hippocrates Oath and code of ethics: In the context of doctors' strike, the significance and meaning of the Hippocratic Oath deserves more attention. The Hippocratic Oath, the first reflective code of professional ethics, is historically taken by doctors swearing to practice medicine ethically. It enables doctors to adopt a more humane and professional approach to the service. Considering the Hippocratic Oath as a core of the medical profession makes the physicians' action at work a central issue to the discussion. Pellegrino clearly emphasizes the importance of the Hippocratic Oath - Without the Oath the doctor is a skilled technician or laborer whose knowledge fits him for an occupation but not a profession........ When the Oath is proclaimed, if it is taken seriously as a binding commitment to place one's special knowledge and skill at the service of the sick, the graduate has then made his 'profession' [40]. He or she enters the company of others with similar commitments. At this moment, one enters a moral community whose defining purpose is to respond to and to advance the welfare of patients - those who are ill, who are in need of help, healing, or relief of suffering, pain or disability. Thus his or her commitment becomes ethically challenging for any activity like strike with a focus on personal and financial gain of doctors at the expense of treating patients [17] and violates ethical codes of the conduct of his or her service. Further, different Codes of Medical Ethics [43] have also been controlling, directing and guiding doctors in various aspects including refrain from staging collective actions.
In India, there are various laws and regulations which also exist to control such collective actions by health care professionals including the national constitution. In a historic judgment in 2003 involving the striking government employees in Tamil Nadu, the Supreme Court ruled that Government employees cannot take society at ransom by going on strike [44]. This ruling refers to the moral duties of public employees, such as doctors, concerning the fact that they have no legitimate claim to go on a strike and take the helpless patients at ransom to meet their demands with the government [45]. In the 'Code of Ethics and Regulations' framed under the Medical council of India (MCI) Act, it is unconditionally stated that medical doctors cannot refuse treatment to any patient who is in need of emergency medical care and once a physician has undertaken a case, he or she should not neglect the patient, nor he / she should withdraw from the case without giving adequate notice to the patient and the family [43]. In December 2010, the Delhi Medical Council issued a statement in response to doctors' strike at the Safdarjung Hospital mentioned that it violates the Indian Medical Council (Professional Conduct, Etiquette and Ethics) Regulations and so under no circumstances doctors should resort to strike [27]. Further, in India, the Essential Services Maintenance Act (ESMA), 1981 enables the government to ban strikes and demand conciliation or arbitration in certain essential services to maintain proper functioning of the community [46]. In this Act, 'essential services' incorporates any service connected with the maintenance of public health and sanitation including hospitals and dispensaries. Laws like ESMA are not implemented effectively to minimize the negative impact to the public and/or end the strikes.

2c. Non-maleficence and beneficence: In essence, all strikes are against someone and causing harm to somebody directly or indirectly. The first moral reason constituting the 'deliberative presumption' (the principles that govern our moral life) against physicians' strike is that physicians cause harm to patients through their strikes and harm to patients ranges from physical injury to psychological stress or anxiety to prolonged pain and suffering to added expense in accessing care [23]. Further, doctors' strike may cause anger, resentment, fear, or mistrust in patients. The principle of non-maleficence is more important in this context. It imposes an obligation not to cause harm on others and in biomedical ethics it has been closely associated with the maxim primum non noncere meaning 'above all do not harm' [47]. Considering this principle, it is apparent that doctors' strike definitely harms patients in one way or another. Similar to the principle of nonmaleficence, Mahabharata; one of the two major Sanskrit epics of ancient India says "This is the sum of duty. Do not do unto others that which would cause you pain if done to you." [48].

Beneficence, referring to actions that promote the wellbeing of others, is considered as one of the core values of health care ethics [47]. In the medical context, this means taking actions that serve the best interests of patients (Salus aegroti suprema lex). 'Wellbeing' of the patient is the ultimate goal of medical profession. All health care systems revolve around this core principle. Hence, how can a striking doctor serve the well-being of patients? Whether doctors' strikes are justifiable if strike is helpful to improve the well-being of future generations especially patients?

2d. Autonomy: Autonomy is one of the most discussed principles in biomedical ethics. The autonomous individual acts freely in accordance with a self-chosen plan [47] and respecting autonomy involves acknowledging value and decision making rights of person and enabling them to act autonomously. Here, doctors are autonomous to do work or not, and have right to conduct strike [49] for their needs 
and resolving problems in their professional situations, especially in a democratic country. Are they autonomous like other professionals to carry out strike by neglecting patient's dependent condition? The new organizational changes are having profound effects on professional autonomy and accountability in virtually every aspect of patient care [16].

In medical profession, there is a set of shared ethical values and they over all relate to the saving of life, the healing of the sick, the wellbeing of the patients and the special responsibility of doctors for their patients [50].

2e. Deontological versus utilitarian reasoning: Deontological reasoning refers to duty, which is usually determined without regard to circumstances or consequences. According to Kant, man is subject to the moral law; since man is a moral agent, he is responsible for his actions. It is a way of judging 'moral correctness' of an action, based on whether or not the action follows established rules. In other words, the ends do not justify the means. Here, strikes are considered as means in democratic society to achieve certain ends. In this context all over the world, doctors' strikes are ethically not justified since they 'use' or 'instrumentalize' patients in order to improve their situation [23]. As opposed to this, many contemporary ethicists and philosophers are in line with utilitarian theories which seem to be an effective tool to assess a specific action in terms of its utility [51]. Utilitarian reasoning always considers circumstances and consequences. According to utilitarianism, actions are right insofar as they tend to promote the greatest happiness for the greatest number, and wrong as they tend to promote the opposite [52]. Nevertheless, there are many situations in which maximizing happiness (improvement of health care system due to strike) could conflict with other values and principles, namely nonmaleficence. However, in a context of doctor's strike, weighing the benefits with harm is a problematic issue when the strikes end up with success which may give benefit to a large group of future patients. All these general ethical reflections on physicians' strike can be useful to assess Indian doctors' striking activities in their specific context.

\section{Ethical analysis for doctors' strike in India}

Considering various ethical reflections on doctors' strike, an ethical evaluation of Indian doctors' strike is possible. However, it is impossible to reach an agreement regarding the justification because of the relative importance of various features and different aspects including social, economic, legal and cultural aspects of India and Indian health care system. We need to assess the physicians' strikes closely including the reasons and arguments for and against, and only then can we reach a conclusion regarding whether those strikes are morally acceptable or not.

Goold pointed out that there are a number of rationales that could be used to justify strikes by physicians [1]. The majority of doctors' strikes in India in the recent past were for the improvement of salary or stipend, and junior or resident doctors are the leading groups in most of these strike scenarios. The wages for doctors working in the Indian public health sector are very low compared to that of their counterparts in most other countries. In addition, the salary of doctors in the public health care system is always many fold less than that of private hospitals in India.

Considering Hippocrates oath and the importance of the term 'profession' in the medical field, two arguments can be put forwarded in order to assess the doctors' strike in India. In one sense, 'profession' emphasis a promise (profession), a vow to dedicate oneself to the good or wellbeing of the patient which stress on the overall fulfillment of some broad societal need. In another sense 'profession' is a job, which has many rights and duties. Duty of a doctor is for the patient's rights to have their wishes respected and observed [53]. Here, the first condition closely adheres to the Hippocratic Oath which gives commitment to the well-being of patient and thus considering deontological reasoning, strikes are morally not allowed; promise is always a promise. Pellegrino emphasised that the well-being of the patients lie less in the expertise of the concerned physicians than in their dedication and commitment to something other than self-interest while providing their services [40,54].

Dedication and compassion have always been promoted as important virtues in Indian medicine. Charaka Samhita, an ancient and authoritative text book on Indian traditional medicine (Ayurveda), prescribes an elaborate Indian code of conduct and it emphasize that medical profession has to be motivated by "bhuta-daya", compassion for living beings. Charaka Samhita also pointed out the significance of dedication of physicians as "Day and night, however thou mayest be engaged, thou shalt endeavor for the relief of patients with all thy heart and soul. Thou shalt not desert or injure thy patient for the sake of thy life or thy living" [55]. It has also been reported that in ancient India, Hindu doctors even took Hindu physician Oath, which also stressed the wellbeing of the patient and the oath summarizes the love as the anchor in the medical practice [56] which prevents doctors abstaining from their duty. Thus, the practice of doctors' strikes is not compatible with the Indian cultural and traditional health care ethics.

Beauchamp \& Childress [47] emphasize that substantially autonomous actions are possible, but being fully autonomous is a utopian deal. Therefore, doctors' right to strike should never conflict and override with the patients' right to access health care since they are more dependent and vulnerable. Moreover, use of one's right (doctors) to strike will violate the fundamental rights of the other (patients) to the extent that it even denies them right to live, apart from their rights to proper health care. In such situation, the Indian Government can legally use laws like the Essential Services Maintenance Act (ESMA), 1981. The doctor must act within the law [57]. It enables the government to maintain a normal condition in the health care system which may also create stress and conflicts among striking doctors.

Considering the qualification, knowledge, risk of the job and expertise needed, doctors are entitled to get decent payment and good labour conditions and in order to achieve such primary goals they have a right to strike. But, as opposed to, for instance factory labourers, the legitimate goals of improving payments and working conditions, are achieved by harming patients. In public hospitals, the patients are coming from poor financial and social backgrounds and most of them are vulnerable people including elderly. They would be harmed in different ways because of the strike.

From a utilitarian perspective a weighing of goods versus harms might result in an ethical justification of a strike. That could be the case, if the strike ends up with success by getting fair wage to doctors and providing better working conditions and overall improvement of the infrastructure of the health care system which would definitely benefit a large group of patients. This benefit would result not only into the improvement of the health care system as a whole but also into a reduction of the 'brain drain' and, thus, the medical profession would become more attractive and acceptable. Huge ethical problems also exist when there are too few doctors to attend to too many patients in the Indian context and if such problems are resolved, it would also improve the patient-doctor ratio. Overall, such radical change results 
in the improvement of the quality of care with definite long term positive implication for the future patients also. In such context, based on utilitarian reasoning, harming a small group of patients at present for the benefit of very large group of future population overweighed. Doctors' strike would be morally acceptable if they can also provide proper medical care for emergency patients during their striking period. Strikes for the policy issues in India $[4,5,10,24]$, are always an eye opener for government and which would result to the benefit of a large population of future medical students in order to get admission in post graduate studies and appointment in government sector without consideration of any class and creed. Thus, considering utilitarian argument that, at times, it is permissible to harm a few for the benefit of many. In such context, Indian doctors' strikes are acceptable.

The mode of strike also plays a crucial role for the ethical discussion on doctors' strike. Usually every person who participates in strikes wants to implement more aggressive strike strategy to get more attention and quicker results. If doctors' strike exceeds a certain limit to harm more patients which will definitely get resistance from both public and government and also leads to further ethical issues. If their mode of strike would be more self-harming type other than harming more patients, for instance conducting a 'hunger strike', a non-violent resistance in which participants fast as an act to achieve a goal, a Gandhian way of strike, can be acceptable without affecting the patients much. Gandhi emphasized the importance of fasting during a hunger strike as "under certain circumstances, fasting is the one weapon God has given us for use in times of utter helplessness" and it is one of the profound ways to draw attention to an issue [58]. Such strikes can be acceptable, if they work and do usual jobs and people will also support the doctors for achieving their needs [33].

Frequent strike reported from health care system in a specific region or specific group like resident doctors reveals mainly the problems and inadequacy of the health care system $[28,59]$. Therefore, a permanent solution is needed to solve the basic problems such as fair wage, providing necessary security, improving infrastructure, developing appropriate policy etc. to avoid frequent strikes in health care services especially by the doctors. Thus necessary care must be taken to uphold decent level of health care system by government in terms of justice. All the third world countries experience the same dilemma which is mostly not because of the governments' non willingness, but they do not possess sufficient resources to pay the doctors in a way that would equal to that of developed countries. Here a balancing exercise is more preferred to reduce inequality and injustice in terms of resource allocation.

\section{Conclusion}

In Indian health care system, doctors' strikes are common and have increasing frequency. Considering inadequacies of Indian health care system, doctors' strike render the situation more grievous. A general ethical reflection is developed based on different normative frame work and biomedical principles, and is used to assess the Indian doctors' strike. Irrespective of any reason such strikes are morally not acceptable in deontological reasoning, further, ethically not allowed in terms of Hippocratic tradition. Considering biomedical principles like beneficence and non-beneficence, such strikes are morally not accepted. This assumption is also well supported by ancient Indian philosophies. Various codes and acts also prevent them from strikes in medical care. However, though most of their reasons are fairish in respect to specific Indian health care system, drawing on utilitarian argument it might by justified to strike for fair wages and better working conditions if it causes less harm to present patients and gives more goods to future patients. Modes of strikes also have important role in the evaluation of strikes. An appropriate ethical frame work should be developed to prevent doctors from collective actions. In order to make health care system more efficient and problem free, government should develop appropriate strategies to support health care workers and it should be reviewed intermittently so that the frequency and the severity of medical strikes will be minimized in the future.

\section{Competing interests}

The authors declare that they have no competing interests.

\section{Authors' contributions}

SV and RPA conceived of the study and drafted the manuscript. RPA worked for the final draft of the manuscript. Both authors reviewed and approved the final manuscript.

\section{Acknowledgements}

This work is a part of Erasmus Mundus Master of Bioethics (EMMB) programme. We highly appreciate the mentorship of Martien Pijnenburg from Radboud University for this work. His untimely death bereaved us. We would like to thank Dr. Rajeev and Dr. Simon T.D. for their valuable feedback on the draft manuscript.

\section{References}

1. Goold SD (2000) Collective action by physicians: beyond strikes. Camb Q Healthc Ethics 9: 498-503.

2. Lokhandwala Y (1996) Should doctors strike work? Issues Med Ethics 4: 47-48.

3. Hadzibegovic I, Danic A, Hren D (2004) Medical Students' opinion on Physicians' strike: Cross sectional questionnaire study. Croat Med J 45: 63-66.

4. Tahir M (2006) Medical strikes in India. Lancet 368: 643.

5. Chatterjee $P$ (2006) India's doctors protest over caste quota plans. Lancet 367: 1892.

6. Srinivasan S (2006) Yet another resident doctor's strike in Maharashtra. Natl Med J India 19: 115.

7. Thomas G (2006) Junior doctors, strike and patient care in public hospitals. Indian J Med Ethics 3: 44-45.

8. Janus K, Amelung VE, Gaitanides M, Schwartz FW (2007) German physicians "on strike" - Shedding light on the roots of physician dissatisfaction. Health Policy 82: 357-365.

9. Harvey M, Shaar MA, Cave G, Wallace M, Brydon P (2008) Correlation of physician seniority with increased emergency department efficiency during a resident doctors' strike. N Z Med J 121: 59-68.

10. Sharma V, Aggarwal S (2009) Residents' strikes on policy issues. Indian J Med Ethics 6: 45-46.

11. García RA (2012) Privatisation in Spain provokes protests among doctors. BMJ 345: e7655.

12. Shukla S (2012) Violence against doctors in Egypt leads to strike action. Lancet 380: 1460.

13. Kravitz RL, Linn L, Tennant N, Adkins E, Zawacki B (1990) To strike or not to strike? House-staff attitudes and behaviors during a hospital work action. West J Med 153: 515-519.

14. Frizelle F (2006) Is it ethical for doctors to strike? N Z Med J 119: U2037. 
15. Robinson G, McCann K, Freeman P, Beasley R (2008) The New Zealand national junior doctors' strike: implications for the provision of acute hospital medical services. Clin Med 8: 272-275.

16. Reitemeier PJ (2000) Collective protest actions by licensed health professionals. Camb Q Healthc Ethics 9: 449-459.

17. Park JJ, Murray SA (2014) Should doctors strike? J Med Ethics 40: 341-342.

18. Grosskopf I, Buckman G, Garty M (1985) Ethical dilemmas of the doctors' strike in Israel. J Med Ethics 11: 70-71.

19. Mawere M (2010) Are physicians' strikes ever morally justifiable? A call for a return to tradition. Pan Afr Med J 6: 11.

20. Thompson SL, Salmon JW (2006) Strikes by physicians: A historical perspective toward an ethical evaluation. Int J Health Serv 36: 331-354.

21. Ekbal B (2012) IMA strike: need for public debate. Indian J Med Ethics 9 226-228.

22. Arun M, Bankura BS, Senthilkumaran S, Sandeep M, Rao PJ, et al. (2011) The recent doctors' strikes in India: a point of view. Med Leg J 79: 129-134.

23. Fiester A (2004) Physicians and strikes: can a walkout over the malpractice crisis be ethically justified? Am J Bioeth 4: W12-16.

24. Nagasaila D, Suresh V (1999) Medico's strike against privatization. Economic and political weekly 27: 2585-2586.

25. Pandya SK (2000) Strikes by physicians in public hospitals in India. Camb Q Healthc Ethics 9: 460-469.

26. Chima SC (2013) Global medicine: is it ethical or morally justifiable for doctors and other healthcare workers to go on strike? BMC Med Ethics S1: S5.

27. Selemogo M (2014) Criteria for a just strike action by medical doctors Indian J Med Ethics 11: 35-38.

28. Aggarwal S, Yadav R, Singh H, Sharma A, Sharma V (2012) Analysis of physicians' strikes and their impact. Indian J Med Ethics 9: 217-218.

29. Mudur G (1996) Doctors on hunger strike in Bombay. BMJ 312: 73.

30. Dasgupta S (2014) Reforms in medical education: optimizing quantity and quality. Indian J Public Health 58: 1-4.

31. Bagcchi S (2015) India has low doctor to patient ratio, study finds. BMJ 351: h5195.

32. Loewy EH (2000) Of healthcare professionals, ethics and strikes. Camb Q Healthc Ethics 9: 513-520.

33. Mallapaty S (2014) Lone hunger striker spurs Nepal to action. Nature 506: 279 .

34. (2015) UNDP Millenium Development Goals.

35. Glick S, Schwarzfuchs D (2012) Physicians' strikes--ethical considerations. Harefuah 151: 12-15, 63.

36. Daniels N (1978) On the picket line: are doctors' strikes ethical? Hastings Cent Rep 8: 24-29.

37. Sachdev PS (1986) Doctors' strike--an ethical justification. N Z Med J 99: 412-414.
38. Jackson RL (2000) Physician strikes and trust. Camb Q Healthc Ethics 9: 504-512.

39. Braithwaite SS (2000) Collective actions by physicians that do not endanger patients. Camb Q Healthc Ethics 9: 470-482.

40. Pellegrino ED (2002) Professionalism, profession and the virtues of the good physician. Mt Sinai J Med 69: 378-384.

41. Cruess RL, Cruess SR (2011) Commentary: professionalism, unionization, and physicians' strikes. Acad Med 86: 548-551.

42. Li ST, Srinivasan M, Der-Martirosian C, Kravitz RL, Wilkes MS (2011) Developing personal values: trainees' attitudes toward strikes by health care providers. Acad Med 86: 580-585.

43. (2002) Medical Council of India. Code of Ethics Regulations.

44. (2003) Supreme Court of India TK Rangarajan vs Government of Tamil Nadu \& Others on 6 August, 2003. Appeal number 5556.

45. Saha K (2009) View Point: Doctors' strike in Bihar. Central Chronicle.

46. (1988) The Essential Services Maintenance Act, 1981.

47. Beauchamp TL, Childress JF (2009) Principles of biomedical ethics. (6th edn.), Oxford University Press, New York.

48. (2015) Golden Rule Project.

49. Abbasi IN (2014) Protest of doctors: a basic human right or an ethical dilemma. BMC Med Ethics 15: 24.

50. Kennerly JA (1993) Professional autonomy in the medical field. J Manag Med 7: 43-47.

51. Petrini C (2010) Theoretical models and operational frameworks in public health ethics. Int J Environ Res Public Health 7: 189-202.

52. Lyon D (2001) Utilitarianism. In: Encyclopedia of Ethics. Becker L, Becker C, (Edn.), Routledge- Taylor \& Francis, New York, USA, 3: 1737-1744.

53. Myers John B (2015) Erratum to "Is alzheimer's disease an adaptability disorder? What role does happiness have in treatment, management and prevention." World J Neurosci 5: 180-188.

54. MacDougall DR (2013) Physicians' strikes and the competing bases of physicians' moral obligations. Kennedy Inst Ethics J 23: 249-274.

55. Reich WT (1995) Oath of Initiation (Charaka Samhita) In: Encyclopedia of Bioethics (edn.), Simon and Schuster MacMillan, New York.

56. Manickavel V (1999) Love in medical ethics in South Asia. Eubios J Asian Int Bioeth 9: 40-42.

57. Myers J (2014) Medical Ethics: Context is the key word. International J Clinic Med 5: 1030-1045.

58. Gandhi MK (1951) Gandhi's letters to a disciple. Harper and Brothers publishers, New York.

59. Weil LG, Nun GB, McKee M (2013) Recent physician strike in Israel: a health system under stress? Isr J Health Policy Res 2: 33. 